\title{
Bibliometric Analysis of Financial Technology
}

\author{
Qingjun $\mathrm{Li}^{1}$, He Lv ${ }^{1}$, Xuzhi Sun², Xiaoxia Guo ${ }^{3, *}$ \\ ${ }^{1}$ Postdoctoral Research Workstation, Bank of Weifang Co., Ltd., Weifang 261041, China \\ ${ }^{2}$ Fenghuang Street Hospital of Fangzi District, Weifang City, Weifang 261200, China \\ ${ }^{3}$ Media and Communication College of Weifang University, 261061, China \\ *Corresponding author. Email: 33104731@qq.com
}

\begin{abstract}
In order to reveal the research status, research hotspots, evolution rules and future research directions in the field of financial science and technology, this paper takes Web of Science database as the sample data source, uses bibliometric analysis method and CiteSpace visualization software, presents the literature co-citation network, highfrequency keyword co-occurrence network and keyword time zone map in the form of knowledge map in the field of financial technology. The results show that the field of financial technology has roughly experienced 27 years of research process, which can be divided into initial embryonic stage, steady development stage and rapid development stage. Among them, from 2013, the literature in the field has shown a trend of rapid growth. The United States and the University of London are the countries and organizations with the largest number of papers published in this field, respectively. Ticknor's papers are cited the most, and fintech is the highest frequency co-occurrence keyword. At the same time, the study also found that financial technology as a keyword first appeared in 2006. These results will provide an important theoretical reference for the research in the field of financial technology.
\end{abstract}

Keywords: Financial technology, Knowledge graph, Fintech, Literature bibliometric.

\section{INTRODUCTION}

With the development of science and technology, science and technology has been gradually applied to various fields. The financial industry is also an important representative of science and technology application. The application of science and technology has brought innovation to the financial industry, and also promoted revolutionary changes in the financial industry. This is the combination of finance and technology; the concept of financial technology came into being. Bettinger (1972) [1] put forward that financial technology is to "combine the professional knowledge of banks with modern management technology and computers". Financial technology is reshaping the global financial system, which will have a subversive impact on traditional finance. Therefore, scholars also began to pay attention to the research of financial technology. Puschmann (2017) [2] believed that the innovation objects of financial technology mainly include five categories. Gai et al. (2018) [3] puts forward a data-driven financial technology theoretical framework, and summarizes the connotation of financial technology from five aspects. Qi and Xiao (2018) [4] studied the cost of financial intermediation. Gimpel et al.
(2018) [5] studied the consumer oriented financial technology start-ups. Gozman et al. (2018) [6] believe that financial technology can bring about the reconstruction of financial services. Jagtiania and Lemieuxb (2018) [7] found that financial technology can significantly reduce transaction costs, expand market capacity, and improve the efficiency of resource allocation of the financial system.

There is also a lack of systematic literature review in the field. Therefore, based on the above shortcomings, this paper uses bibliometric methods to summarize the research status, hot spots and trends of financial technology from multiple dimensions, to provide reference for the academic community to continue to carry out relevant research.

\section{METHOD}

This paper uses bibliometric analysis method and knowledge mapping visualization analysis tool to systematically comb the related literature in the field of virtual academic community, and grasps the research status in the field, the overall publishing trend of literature, the distribution of countries or regions, the distribution of source publications, the analysis of 
highly cited literature, the analysis of co-occurrence keywords and the time zone analysis of keywords. Using the method of bibliometric analysis, this paper makes a statistical analysis on the number of literatures published, the number of national institutions (regions), the co-cited high-frequency literature and highfrequency co-occurrence keywords. At the same time, CiteSpace software is used to generate the co citation network, high-frequency keyword co-occurrence network and keyword timeline by setting relevant thresholds[8].

The sample literature of this paper is mainly from the web of science database. In order to ensure the accuracy of the retrieval, the scholars conducted a pre search before the formal retrieval, found out the highly cited literature, followed up and determined the accurate retrieval keywords or keywords. After screening, 1367 samples were obtained as the sample data of this paper.

\section{RESULTS}

\subsection{General Trend of Literature Publications}

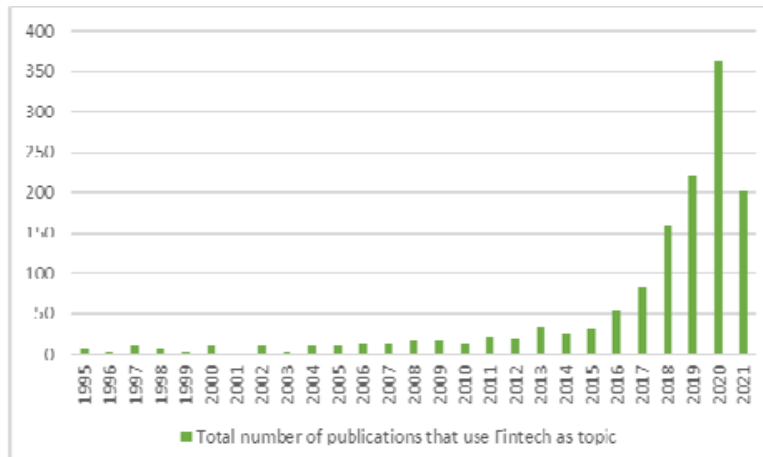

Figure 1 Time distribution of literature quantity.

It can be seen from Figure 1 that the number of published literatures from 1995 to 2003 was at a low level. Except for 1997, the number of published literatures was no more than 10 every year, indicating that the research of financial technology was in an initial embryonic stage during the nine years, and scholars began to explore the related concepts of financial technology. Since 2004, the number of literatures has been increasing. Until 2012, the number of literatures is basically at a stable level. The number of published literatures is no less than 10 every year, but the number of published literatures is less than 20 every year except 2011. This shows that the research of financial technology is in a steady development stage during the nine years, Scholars' research on financial technology has entered a more in-depth research stage. Since 2013, the number of literatures has increased rapidly, from 33 in 2013 to 362 in 2020, with an annual average of more than 130 literatures published. Due to the retrieval time node, the number of literatures published in 2021 was only counted to July of that year, but the number of literatures published in these seven months has exceeded 200, which indicates that during the nine years, the number of literatures published has increased rapidly, and the research of financial technology has entered a stage of rapid development. Scholars put more vigor in the research of financial technology, the number of literatures is more abundant, and the research heat continues to increase. Therefore, from the perspective of time, this paper divides the research of financial technology into three stages: the first stage: the period from 1995 to 2003, which belongs to the initial embryonic stage; the second stage is the period from 1995 to 2003; The second stage: from 2004 to 2012, it belongs to the stage of steady development; The third stage: 2013-2021, belongs to the rapid development stage.

\subsection{Distribution of Countries (Regions) and Organizations}

Table 1. Number of documents in major countries/regions and organizations

\begin{tabular}{|c|c|c|c|c|}
\hline $\begin{array}{l}\mathrm{Ra} \\
\mathrm{nki} \\
\mathrm{ng}\end{array}$ & $\begin{array}{c}\text { Countri } \\
\text { es/Regi } \\
\text { ons }\end{array}$ & $\begin{array}{c}\text { Record } \\
\text { Count }\end{array}$ & Organizations & $\begin{array}{l}\text { Record } \\
\text { Count }\end{array}$ \\
\hline 1 & $\begin{array}{l}\text { Peoples } \\
\text { R China }\end{array}$ & 805 & Chinese Academy of Sciences & 292 \\
\hline 2 & USA & 700 & $\begin{array}{c}\text { University of Chinese Academy of } \\
\text { Sciences }\end{array}$ & 105 \\
\hline 3 & $\begin{array}{c}\text { Australi } \\
\text { a }\end{array}$ & 236 & Beijing Normal University & 80 \\
\hline 4 & England & 184 & University of California System & 78 \\
\hline 5 & Canada & 157 & $\begin{array}{l}\text { Institute of Geographic Sciences } \\
\text { Natural Resources Research CAS }\end{array}$ & 72 \\
\hline 6 & $\begin{array}{c}\text { German } \\
\mathrm{y}\end{array}$ & 151 & Hohai University & 70 \\
\hline 7 & India & 129 & $\begin{array}{c}\text { Commonwealth Scientific\& } \\
\text { Industrial Research Organisation } \\
\text { (CSIRO) }\end{array}$ & 63 \\
\hline 8 & $\begin{array}{l}\text { South } \\
\text { Africa }\end{array}$ & 128 & $\begin{array}{l}\text { China Institute of Water Resources } \\
\text { and Hydropower Research }\end{array}$ & 59 \\
\hline 9 & Iran & 111 & $\begin{array}{l}\text { United States Department of } \\
\text { Agriculture }\end{array}$ & 52 \\
\hline 10 & Italy & 104 & $\begin{array}{c}\text { French National Scientific Research } \\
\text { Centre }\end{array}$ & 48 \\
\hline
\end{tabular}

Table 1 shows the number of papers issued by countries (regions) and organizations in the field of financial technology. It can be seen from Table 1 that among the top 10 countries (regions) in the total number of papers published, the United States has the largest number of papers in the field of financial technology, accounting for $24.7 \%$ of the total number of papers published; China ranked second, England ranked third. Among the top 10 organizations in the total number of 
papers published, China, the United States, the United Kingdom and Australia have two organizations; Among them, the University of London published 36 papers, followed by the University of Hong Kong and the University of New South Wales Sydney, with 21 papers.

\subsection{Source Publication Distribution}

Table 2. Top 10 publications with Fintech

\begin{tabular}{|c|c|c|c|}
\hline Publication Name & $\begin{array}{c}\text { Record } \\
\text { Count }\end{array}$ & Publication Name & $\begin{array}{c}\text { Record } \\
\text { Count }\end{array}$ \\
\hline Sustainability & 32 & $\begin{array}{c}\text { Routledge International } \\
\text { Studies in Money and } \\
\text { Banking }\end{array}$ & 12 \\
\hline $\begin{array}{c}\text { Electronic Commerce } \\
\text { Research and Applications }\end{array}$ & 14 & $\begin{array}{c}\text { European Business } \\
\text { Organization Law Review }\end{array}$ & 11 \\
\hline $\begin{array}{c}\text { Technological Forecasting } \\
\text { and Social Change }\end{array}$ & 13 & $\begin{array}{c}\text { European Journal of } \\
\text { Finance }\end{array}$ & 10 \\
\hline IEEE Access & 12 & Quantitative Finance & 10 \\
\hline $\begin{array}{c}\text { Rise and Development of } \\
\text { Fintech Accounts of } \\
\text { Disruption from Sweden } \\
\text { and Beyond }\end{array}$ & 12 & Financial Innovation & 9 \\
\hline
\end{tabular}

Table 2 shows the top 10 source publications in the field of financial technology. It can be seen from Table 2 that "Sustainability" has published 32 academic papers on financial technology, with the largest number of published papers. The second is "Electronic Commerce Research and Applications" and "Technological Forecasting and Social Change", with 14 and 13 papers respectively.

\subsection{Analysis of High Frequency Cited Literatures}

Table 3. Top 10 of high frequency cited literatures

\begin{tabular}{|c|c|c|}
\hline Authors & Source Publication & $\begin{array}{c}\text { Times } \\
\text { Cited }\end{array}$ \\
\hline Ticknor et al. & $\begin{array}{c}\text { EXPERT SYSTEMS WITH } \\
\text { APPLICATIONS }\end{array}$ & 220 \\
\hline Das et al. & JOURNAL OF MANAGEMENT & 206 \\
\hline Stafford-Smith et al. & SUSTAINABILITY SCIENCE & 178 \\
\hline Lee et al. & BUSINESS HORIZONS & 100 \\
\hline Haddad et al. & SMALL BUSINESS ECONOMICS & 60 \\
\hline Leijten et al. & HEALTH POLICY & 47 \\
\hline Chen et al. & REVIEW OF FINANCIAL STUDIES & 46 \\
\hline Platanakis et al. & BRITISH ACCOUNTING REVIEW & 31 \\
\hline McDonald et al. & $\begin{array}{c}\text { ADMINISTRATIVE SCIENCE } \\
\text { QUARTERLY }\end{array}$ & 30 \\
\hline Thakor et al. & $\begin{array}{c}\text { JOURNAL OF FINANCIAL } \\
\text { INTERMEDIATION }\end{array}$ & 30 \\
\hline
\end{tabular}

Table 3 shows the 10 most frequently cited papers in the field of financial technology. As shown in Table 3, Ticknor et al. Published in the journal "EXPERT SYSTEMS WITH APPLICATIONS" in 2013 had the highest number of citations, reaching 220. Secondly, Das et al. Published papers in "JOURNAL OF
MANAGEMENT” in 1998, which were cited 206 times. The papers published by Stafford-Smith in the journal "SUSTAINABILITY SCIENCE" in 2017 were cited 178 times. The number of cited papers ranked in the 4th to 10 th place was $100,60,47,46,31,30$ and 30 respectively.

\subsection{Analysis of Co-occurrence Keywords}

Keyword co-occurrence analysis is based on the generation of co-occurrence network to analyze the frequency of keywords in the literature. Figure 2 shows the clustering of co-occurrence keywords, that is, the knowledge map of co-occurrence keywords. As can be seen from Figure 2, deep learning, banking strategy, climate change, financial function and financial development are the five least numbered keywords cluster, it indicates that the clustering of these five keywords is the research hotspot in the field of financial technology, and the frequency of these five keywords is the highest.

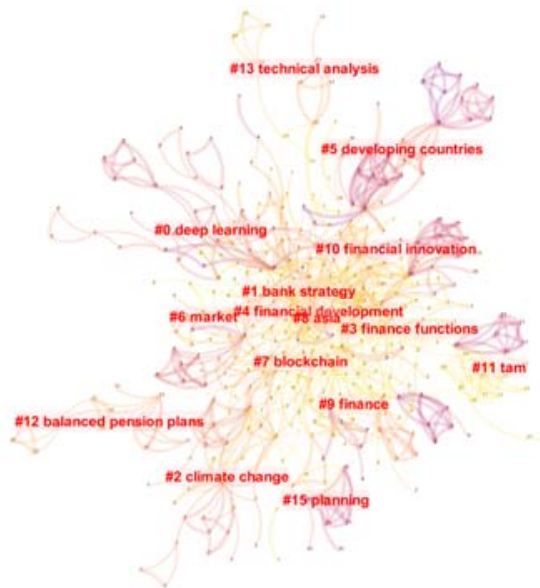

Figure 2 Knowledge graph of keywords co-occurrence.

Table 4 selects the top 10 high-frequency cooccurrence keywords. The top five are the "fintech" (50 times), "financial technology" (61 times), "innovation" (45 times), "model” (27 times) and "blockchain” (24 times). High centrality represents a high key position in the co-occurrence network. At the same time, it reflects a high degree of cooperation in the field. It can be seen from Table 4 that the centrality of the current keywords is 0 . This shows that there is no special focus in the field of financial technology. In the research field of financial technology, fintech, financial technology, innovation, model, blockchain, risk, technology, market, impact and finance are the top ten research hotspots in this field. 
Table 4. High frequency co-occurrence keywords

\begin{tabular}{|c|c|c|c|}
\hline Year & High Frequency Co-occurrence Keywords & Centrality & Count \\
\hline 2016 & fintech & 0 & 79 \\
\hline 2006 & financial technology & 0 & 61 \\
\hline 2013 & innovation & 0 & 45 \\
\hline 2000 & model & 0 & 27 \\
\hline 2017 & blockchain & 0 & 24 \\
\hline 2004 & risk & 0 & 23 \\
\hline 2013 & technology & 0 & 23 \\
\hline 2000 & market & 0 & 20 \\
\hline 2012 & impact & 0 & 19 \\
\hline 2004 & finance & 0 & 17 \\
\hline
\end{tabular}

\subsection{Time Zone Analysis of Keywords}

The time zone analysis of keywords reflects the year when the keywords first appear and the changes in the time axis, so that we can observe the new keywords as time goes on, so as to understand the current research hotspots [9]. It can be seen from Figure 3 that high frequency keywords mainly appear in 2000-2021, and during these years, new keyword appears every year. Financial technology as a keyword first appeared in 2006.

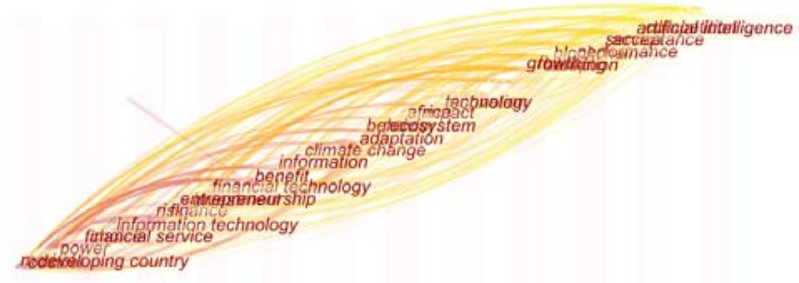

Figure 3 Time zone graph of keywords.

\section{CONCLUSIONS}

The paper takes Web of Science database as the sample data source, uses bibliometric analysis method and CiteSpace visualization software, presents the literature co-citation network, high-frequency keyword co-occurrence network and keyword time zone map in the form of knowledge map in the field of financial technology. The results show that the field of financial technology has roughly experienced 27 years of research process, which can be divided into initial embryonic stage, steady development stage and rapid development stage. The United States and the University of London are the countries and organizations with the largest number of papers published in this field, respectively. Ticknor's papers are cited the most, and fintech is the highest frequency cooccurrence keyword. At the same time, the study also found that financial technology as a keyword first appeared in 2006.

\section{ACKNOWLEDGMENTS}

This work was supported by Postdoctoral Science Foundation of China (No. 2020M682233) and the Social Science Foundation of Shandong (No. 21CGLJ37).

\section{REFERENCES}

[1] Bettinger A. Fintech: A Series of 40 Time Shared Models Used at Manufacturers Handover Trust Company [J]. Interfaces, 1972(2): 62-63.

[2] Puschmann T. Fintech [J]. Business \& Information Systems Engineering, 2017, 59(1):69-76.

[3] Gai K., Qiu M. K. and Sun S T. A Survey on FinTech [J]. Journal of Network and Computer Applications, 2018, 103(2):262-273.

[4] Qi Y. and Xiao J. Fintech: AI Powers Financial Services to Improve People's Lives [J]. Communications of the ACM, 2018, 61(11): 65-69.

[5] Gimpel H. and Rau D. Understanding Fintech StartUps-A Taxonomy of Consumer-Oriented Service Offerings [J]. Electron Markets, 2018, 28(3): 245264.

[6] Gozman D, Liebenau J, Mangan J. The Innovation Mechanisms of Fintech Start-Ups: Insights from Swift's Innotribe Competition [J]. Journal of Management Information Systems. 2018, 35(1):145-179.

[7] Jagtiania J, Lemieuxb C. Do Fintech Lenders Penetrate Areas that are Underserved by Traditional Banks? [J]. Journal of Economics and Business, 2018, 100(4): 43-54.

[8] Chen, C. M. Science mapping: A systematic review of the literature[J]. Journal of Data and Information Science, 2017, 2(2): 1-39.

[9] Li Q., Guo X., and Zhang L. Bibliometric Analysis of Water Resource Management[J]. Journal of Coastal Research, 2020, 105(sp1): 210-214.337351. 